\title{
Revistas científicas e o movimento
}

\section{Open-Access}

\begin{tabular}{ll}
\hline & Editora Adjunto. Revista Eletrônica \\
& Científica da Uergs. Bibliotecária. \\
& Universidade Estadual do Rio Grande do \\
Simone Semensatto & Sul. Mestre em Comunicação e \\
Informação pela UFRGS.
\end{tabular}

E-mail:simone-semensatto@uergs.edu.br

DOI: 2http://dx.doi.org/10.21674/2448-0479.43.340-342

O Open-Access ou Acesso Aberto de publicações científicas tem sido reconhecido como uma agenda implícita por muitos movimentos, segmentos, órgãos, instituições, e outros setores nacionais e internacionais, relacionados à pesquisa, à produção de conhecimento e às publicações. Importante observar que existem muitos meios de publicar um conteúdo acadêmico, contudo, o artigo científico segue sendo considerado, para a maioria das áreas do conhecimento, o principal meio de divulgação científica pois a avaliação realizada por pares garante maior qualidade a publicação.

A partir dos anos 2000 os custos elevados para a produção e manutenção de periódicos impressos passaram a ser uma preocupação cada vez mais crescente dos órgãos envolvidos com a publicação de periódicos científicos. O programa SciELO (Scientific 
Electronic Library Online) surgiu em 1998 como uma solução para tornar o conhecimento acessível a todos, principalmente aqueles produtos oriundos de verba pública. Tivemos a implementação do Portal de Periódicos da CAPES, no ano 2000, proporcionando aos estudantes de instituições de todo o país o acesso direto aos melhores "journals" de forma a garantir a melhoria da produção científica nacional. Em 2001, a nível mundial, ocorreu um importante evento: o Budapest Open Archives Initiative momento no qual foram definidas duas iniciativas de Open-Access. A chamada via verde (Green Road) que considera o trabalho do autor como autoarquivado, ou seja, o próprio autor pode depositar o seu trabalho em site próprio ou através de outros canais de comunicação e como ocorre atualmente em muitos repositórios institucionais. $\mathrm{E}$ a via dourada (Gold Road) na qual o documento é disponibilizado pelos editores, a exemplo da iniciativa do programa SciELO. Atualmente o SciELO é considerado o maior provedor de periódicos indexados pelo DOAJ (Diretório de Periódicos de Acesso Aberto).

As revistas científicas que disponibilizam livremente os artigos publicados fazem parte do movimento Open-Access, e nesse contexto também nasceu a Revista Eletrônica Científica da Uergs (RevUergs). Além de disponibilizar os artigos em acesso aberto possuímos a preocupação de oferecer um processo de revisão por pares duplo cego (double blind peer review), que prima pela qualificação do referido periódico por meio de indexação e divulgação, consoante com as palavras de uma das Editoras Chefe, Erli Schneider Costa (2016, p.3), "A cada novo número esperamos 
oferecer aos nossos leitores mais artigos de qualidade bem como dar oportunidades aos autores de publicarem em um veículo sério e ético". Para tanto estamos realizando a inclusão da REV-UERGS em bases de dados nacionais e internacionais de forma a divulgar os artigos publicados.

Atualmente a RevUergs é indexada em algumas bases e todos os artigos publicados recebem o registro de DOI (Digital object identifier) que é considerado um registro padrão para identificação de documentos na internet. Existem estudos que comprovam o impacto positivo do Open-Access (PACKER et al., 2014) e percebido por meio do número crescente de acessos e downloads dos artigos, bem como da ampliação das citações. Também há estudos estatísticos de usos de repositórios institucionais, a exemplo do Repositório Digital da Universidade Federal do Rio Grande do Sul (UFRGS), onde é possível verificar os acessos e os downloads do documento no link Estatísticas, acessível a todos.

\section{REFERÊNCIAS:}

COSTA, Erli Schneider. Vida longa à Revista Eletrônica Científica da UERGS. Revista Eletrônica Científica da UERGS, [S.I.], v. 2, n. 1, p. 03-04, abr. 2016. ISSN 2448-0479. Disponível em: <http://revista.uergs.edu.br/index.php/revuergs/article/view/418>. Acesso em: 23 out. 2018. doi:http://dx.doi.org/10.21674/2448-0479.21.03-04.

PACKER, Abel L. et al. (Org). SciELO - 15 anos de Acesso Aberto: um estudo analítico sobre o Acesso Aberto e comunicação científica. Paris: UNESCO, 2014. Disponível em: < http://scielo.org/local/File/livro.pdf> Acesso em: 18 mar. 2018.

UNIVERSIDADE FEDERAL DO RIO GRANDE DO SUL. REPOSITÓRIO DIGITAL LUME. Estatísticas. Itens com mais downloads. Porto Alegre: UFRGS, 2018. Disponível em: < http://www.lume.ufrgs.br/stats/topten> Acesso em: 21 mar. 2018. 